\title{
A Formação Profissional e A Ética na Terapia Sexual
}

\author{
Mônica Rita Bueno Pugliese ${ }^{1}$ \\ Maria Aparecida Fernandes Gomes ${ }^{2}$ \\ Oswaldo Martins Rodrigues Júnior ${ }^{3}$
}

\section{RESUMO}

PUGLIESE, M. R. B.; GOMES, M. A. F.; RODRIGUES Jr., O. M. A formação profissional e a ética na terapia sexual. R. B. S. H. 1(1): 1990.

O bom senso no atendimento aos pacientes com queixas de disfunções e dificuldades sexuais prevalece, igualando-se ao comportamento profissional eticamente desejável entre os profissionais atuantes na área.

A postura profissional ética é adquirida através de formação acadêmica específica. Aqueles que estudam e mesmo procuram se desenvolver no trabalho na área da sexualidade, apesar de conhecerem as técnicas utilizadas em Terapia Sexual, mostram-se deficientes quanto ao conhecimento da complexidade da personalidade humana e do como se trabalhar profissional e terapeuticamente nesta área, sendo necessário o desenvolvimento do respeito profundo ao ser humano como um todo.

Questiona-se uma possível regulamentação e um código específico para o terapeuta sexual através de uma entidade comum aos profissionais do trabalho em sexualidade.

Unitermos: terapia sexual, ética profissional.

1. Bacharel em Psicologia, membro do Centro de Estudos de Sexualidade Humana, do Instituto H. Ellis.

2. Bacharel em Psicologia, membro do Centro de Estudos de Sexualidade Humana, do Instituto H. Ellis.

3. Psicólogo, psicoterapeuta sexual do Instituto H. Ellis, Centro Multidisciplinar para o Diagnóstico e Tratamento em Sexualidade; professor assistente de Psicologia Geral e Teorias e Técnicas Psicoterápicas II e supervisor do curso de Orientação Sexual de Adolescentes das Faculdades São Marcos.

Trabalho desenvolvido para a cadeira de Ética Profissional do curso de Psicologia das Faculdades São Marcos.

Recebido em 19/2/90 


\section{SUMMARY}

PUGLESE, M. R. B.; GOMES, M. A. F.; RODRIGUES Jr., O. M. Ethics in sex therapy and professional skills. R. B. S. H.1(1): 1990.

The commom sense in the work with sexual complaints is used by professionals in the field replacing the desirable professional ethical behavior guidelines as it would be to any profession.

College graduation or post-graduation in mental health is needed to lead to adequated cognitive information, skills and ethics for sex therapy and/or psychotherapy for sexual problems.

Professionals without specific college or post-graduation training in psychotherapy although might have adequated knowledge in sex therapy thechniques, may lack knowledge and skills to treat the human personality as a whole, which will get to a respect to the human being.

The possibility of a ethical policy and a entity that would rule the field is discussed.

Uniterms: sex therapy, ethics.

\section{INTRODUÇÃO}

Etimologicamente, ética (do grego "ethikos") significa modo de ser ou caráter adquiridos e/ ou conquistados pelo homem, estabelecendo na conduta humana os conceitos de bem e de mal, numa determinada sociedade em determinada época.

Estando a ética implícita no cotidiano, por envolver as relações humanas, esta adquire um valor fundamental, principalmente para os profissionais que lidam com o comportamento humano, em especial para as áreas socialmente mais melindrantes que envolvem estruturas contraditórias e, no entanto, fortemente estabelecidas, a exemplo da sexualidade humana.

Este trabalho visa discutir o modo de atuação dos terapeutas sexuais, enfocando a ética profissional e a formação acadêmica: pré-requisitos para a formação do terapeuta sexual; parâmetros de atuação a serem seguidos; possível regularização específica e órgão normativo.

Ressalta-se a especificidade do trabalho psicoterapêutico, pela unicidade do setting terapêutico, com a manutenção da privacidade do cliente/paciente também na terapia sexual. 


\section{O TRABALHO EM SEXUALIDADE E A ÉTICA}

Para se atingir o estágio atual de conhecimento no campo da sexualidade humana, muito contribuíram as pesquisas realizadas por historiadores e antropólogos, revelando as diversas facetas do comportamento e das instituições relacionadas ao sexo, em diferentes épocas e locais (Ellis, 1936; Gregersen, 1983).

Hoje, em nome dos tempos modernos, através de um maior acesso às informações e do desenvolvimento da tecnologia, profundas e generalizadas modificações ocorreram, principalmente na esfera da sexualidade, onde surge o movimento sobre o repensar de valores e preconceitos do indivíduo a/ou da cultura em que se está inserido.

Pensadores voltados para questões existenciais têm mostrado a inutilidade de se tentar impor normas universais e padronizadas de formas de atuação do ser humano, sobretudo no que se refere à sexualidade. “... pois ninguém é o caso particular de uma lei geral, cada pessoa é um universo singularíssimo e irrepetível, toda experiência é uma criação individual que deve ser respeitada em sua peculiaridade e em sua liberdade de ser diferente. E se isso vale para outros níveis, no nível sexual torna-se ainda mais verdadeiro: o perfil erótico de cada um conjuga elementos individuais de experiências vividas, imaginação, gosto, sensibilidade, disposição física, traços psicológicos, padrões estéticos etc..." (Pessanha, 1981, p. IV).

Se enquanto indivíduo de uma sociedade apta à democracia temos o direito de fazer prevalecer nossas diferenças, seja do ponto de vista econômico, social ou cultural, por que não ter o direito às diferenças pessoais no tocante à sexualidade?

Porém, não podemos esquecer que esse mesmo indivíduo com direito às diferenças em qualquer nível de sua existência é o mesmo que procura o profissional com o pedido de ajuda. Até onde se encontra o direito do profissinal de querer padronizar uma conduta sexual, partindo de um único ponto de vista, julgando ser a mais, ou única, saudável ao cliente/paciente com queixas sexuais?

Em resposta a esta pergunta, que põe em jogo uma série de convicções pessoais do psicoterapeuta, consulta-se o Código de Ética Profissional dos Psicólogos (CFP, 1987), artigo 2º alínea "e", das proibições: "... é vedado induzir a convicções políticas, filosóficas, morais ou religiosas, quando do exercício de suas funções profissionais."

Então, torna-se claro que a atuação dos terapeutas sexuais encontra-se enfocada, principalmente, no auxílio ao exorcismo de infundados temores e tabus, fazendo com que o indivíduo necessitado 
de ajuda assuma, de modo consciente e responsável, suas peculiaridades frente à sexualidade. No entanto, a terapia sexual não é uma abordagem onde se faz a indicação de exercícios padronizados do comportamento sexual; nem se trata apenas de uma transposição do que se encontra escrito em livros para os pacientes (se assim o fosse, venderíamos livros a não sessões de psicoterapia). Anti-ética é esta imposição. Ética é a utilização de técnicas numa abordagem geral e humana do paciente.

Ressalte-se que as entrevistas de psicólogos atuantes na área comparadas a de outros profissionais sem formação acadêmica na área de saúde mental (não psicólogos e não psiquiatras), mas que atuam no campo da sexualidade, permitem a reflexão sobre se a ética profissional se trata de um comportamento adquirido a/ou imposto nos bancos escolares superiores em área específica do conhecimento humano, ou se é inerente ao ser humano na atuação profissional com respeito adequado ao paciente/cliente. O profissional que se desenvolveu sob restrita supervisão ética, direcionando-se ao trabalho em sexualidade com a consideração pelo paciente, tende a não cometer atos anti-éticos, enquanto que aqueles sem a devida formação acadêmica em muitos aspectos fogem do compromisso ético ao qual obviamente não se encontram submetidos e com o qual não se compromissaram.

Outro ponto de importância ética, no campo da atuação em sexualidade, é o da indicação de uma conduta terapêutica. Por ser uma área socialmente delicada do comportamento humano, envolvendo ética moral e social, e devido a uma necessidade do pàciente em não se expor em suas deficiências sexuais, por considerar uma ignomínia (principalmente no que diz respeito ao homem portador de disfunção erétil), muitos pacientes são conduzidos a acatar tratamentos inadequados. Estes tratamentos vão desde uma medicação, geralmente inofensiva a de potencial efeito placebo, até cirurgias indesejáveis, passando por várias formas de psicoterapia, muitas vezes alienantes, que se estendem por três ou quatro anos, até que o paciente dela se canse e desista, continuando sua procura de tratamento (Rodrigues Jr. e cols., 1988a, b; Rodrigues Jr., 1989).

\section{CONCLUSÕES}

A psicoterapia voltada para a sexualidade é uma das vertentes da Psicologia que está a cada dia expandindo-se mais. Porém, apesar da rápida expansão que vem tendo esta fatia do trabalho psicoterapêutico, não existe um código de ética específico, tampouco existe 
no Código de Ética Profissional dos Psicólogos (classe específica de psicoterapeutas) algo que seja especificamente dirigido a esta linha de atuação. Ainda está para ser elaborada uma ética adequada e dirigida para a terapia sexual ${ }^{4}$.

Partindo-se da etimologia da palavra ética (modo de ser ou caráter, adquirido ou conquistado pelo homem), na profissão do psicólogo, assim como em tantas outras, tem a função de estabelecer parâmetros para o trabalho profissional. Acredita-se que tais leis servem como um referencial profissional, apesar de se perceber que o que prevalece é o bom senso e o respeito pelo ser humano.

Seria de grande proveito para a classe dos profissionais que trabalham na área de sexualidade humana que estes fizessem reuniões freqüentes, onde pudessem ser discutidas as várias técnicas e teorias que se enquadram mais diretamente ao trabalho a que se propõem e à necessidade da regulamentação de uma entidade de classe que represente e, de certa forma, fiscalize os parâmetros éticos envolvidos neste campo de trabalho tão delicados ${ }^{5}$.

Nota-se a necessidade da confecção de um Código de Ética específico para a abordagem da terapia sexual, posto que o intuito principal das leis contidas no Código de Ética é o de alertar os psicólogos sobre as várias questões da profissão, e não algo específico sobre assuntos interdisciplinares, como o trabalho em sexualidade. Entretanto, também deve-se considerar necessário o maior controle sobre as pessoas que exercem funções nesta área, onde muitos trabalham sem uma formação universitária em saúde mental, em específico em Psicologia ou Psiquiatria, fazendo-se valer de cursos de informação em sexualidade sem a devida formação em psicoterapia, como ocorre nos cinco anos das faculdades de Psicologia ou nos da residência médica em Psiquiatria. Não obstante, tais "profissionais", sem a devida habilitação, outorgam-se o mesmo direito de atuação, na psicoterapia, em um campo tão importante, delicado e complexo como o da sexualidade humana.

Nota-se que qualquer trabalho deve ser inovador e polêmico para produzir desenvolvimento. Ao se falar de sexualidade, as reações mostram se mais conflitantes, naturalmente por fatores cul-

4. Uma discussão foi iniciada por um grupo informal no I Encontro Nacional dos Profissionais da Área de Sexualidade Humana, Faculdades São Marcos, São Paulo, 16-18/04/1988.

5. Talvez seja uma das possíveis funções da Sociedade Brasileira de Sexualidade Humana - SBRASH; proposta que também ocorre em níveis internacionais da International Society for Impotence Reçearch (ISIR) por Sharlip. 1989, De Palma, 1989, Bennet, 1989. 
turais. Como um código específico pode ou deve incluir tais fatores? Uma questão a ser debatida e estabelecida, enquanto ética, é a condução de exercícios de focalização sensorial e outros para o desenvolvimento do comportamento sexual do paciente em tratamento, no consultório. Pode e/ou deve o terapeuta sexual fazer os exercícios com seu paciente (à moda dos parceiros sub-rogados ou suplentes sexuais)? Será um procedimento ético?

Não existe, ainda, uma maneira de controlar efetivamente 0 que acontece no interior do setting psicoterapêutico, porém cabe ao profissional manter o bom senso e o respeito para com o seu cliente/paciente em atendimento naquele espaço e momento.

Os profissionais atuantes demonstraram a preocupação com os caminhos que a terapia sexual vem trilhando desde o seu surgimento. Apesar disso, as reflexões pessoais foram feitas e a atividade prática dos mesmos, de certa maneira, encarregaram-se de mostrar-lhes o caminho mais adequado.

Vários questionamentos foram levantados durante as entrevistas, sendo a maioria concernentes à atitude do terapeuta perante 0 cliente - como lidar com os desejos, os problemas por reprimi-los ou não, as técnicas utilizadas na terapia sexual e como aplicá-las, a formação dos profissionais.

Através desses questionamentos clareamos a posição da atuação dos profissionais de saúde de um modo geral a da atuação do psicoterapeuta aos problemas da área sexual.

Se tomarmos o modelo de Annon (1980) do Pilseti, admitiremos quatro níveis de atuação para o tratamento de problemas sexuais. Os níveis de Permissão e Informação Limitada podem e devem ser utilizados e exercidos por todos os profissionais de saúde e mesmo, em muitas situações pedagógicas, por professores, tratando a sexualidade de uma forma normal e os vários momentos onde preocupações surjam. Os níveis de Sugestões Específicas e Terapia Intensiva só devem ser utilizados, no entanto, por psicoterapeutas treinados. Apesar de haver problemas sexuais que podem ser resolvidos por médicos clínicos, ginecologistas e urologistas e outros com treino em técnicas específicas em sexualidade, há disfunções sexuais que necessitam de treinamento maior e aprofundado em psicoterapia para serem resolvidos (Annon, 1980; Rodrigues Jr., 1989).

Algumas das pessoas sem a devida formação universitária têm a mesma noção de bom senso, moral e ética daqueles devidamente qualificados, porém outras acreditam ser a ética profissional, bem como os artigos do Código de Ética Profissional dos Psicólogos, um ponto irrelevante no trabalho profissional. Estas apenas conhecem as 
técnicas e como aplicá-las. Sem terem desenvolvido a devida competência para trabalhar com os materiais que emergem do inconsciente e com os mecanismos de defesa do ego, podem deixar o paciente vulnerável por não conhecerem a complexidade da personalidade do paciente, desestruturando-o sem que possam reverter o processo de modo adequado, como fariam os profissionais devidamente instrumentalizados e treinados. Muitas vezes estes "profissionais" sem formação e especialização específica em psicoterapia mantêm ligações emocionais-afetivas com seus pacientes, contrariando a alínea " $n$ " do artigo 2ํdo Código de Ética Profissional dos Psicólogos, o qual diz que é vedado ao psicólogo estabelecer com a pessoa do atendido relacionamento que possa interferir negativamente nos objetivos dó atendimento (CFP, 1987).

Deve-se optar por um critério mais rigido para a seleção dos profissionais que atuam na área da sexualidade humana e, mais especificamente, na da terapia sexual, tanto nos bancos acadêmicos como em cursos extra-curriculares ou de especialização oferecidos aos futuros terapeutas, posto que em algumas ocasiões nenhum critério é pré-estabelecido para impedir a participação de estudantes ou de profissionais de outras áreas sem o devido treino em psicoterapia, no caso de cursos de formação em terapia sexual. Não se faz, tampouco, a apologia da necessidade de um Curso de Terapia Sexual, podendo ser a formação no estilo do aprendizado de outras formas de psicoterapia: através de supervisão contínua dos atendimentos até que o terapeuta sinta-se adequado para os atendimentos por si só.

Aos profissionais envolvidos deve-se lembrá-los, no caso dos psicólogos, o artigo 35 do Código de Ética: "O psicólogo não divulgará, ensinará, cederá, dará, emprestará ou venderá a leigos instrumentos e técnicas psicológicas que permitam ou facilitem o exercício ilegal da profissão" (CFP, 1987). Ao se observar tal artigo, impede-se que leigos ou profissionais sem a adequada capacitação acadêmica venham a exercer uma função de terapeuta sexual.

Conclui-se, então, que a base para uma boa formação do psicoterapeuta sexual não está ligada só aos bancos acadêmicos, nem só a estágios, participação em congressos, em simpósios, encontros científicos e profissionais, grupos de estudos, cursos de especialização, atendimentos supervisionados por terapeutas mais experientes e qualquer outra atividade que venha a engrandecer o conhecimento do futuro profissional perante a sociedade. É necessário uma maior união de classe para que, junto aos órgãos competentes, haja representatividade para se lutar pelo espaço de direito e contra a atuação ilegal, inadequada e anti-ética neste campo. 


\section{REFERÊNCIAS BIBLIOGRÁFICAS}

1. ANNON, J. S. Tratamento Comportamental dos Problemas Sexuais. São Paulo, Editora Manole, 1980.

2. BENNET, A. H. Ethical, legal and economic problems in impotence practice. International Journal of Impotence Research (ISIR) $1(3 / 4): 148-9,1989$.

3. CONSELHO FEDERAL DE PSICOLOGIA. Código de Ética Profissional dos Psicólogos. Brasilia, 1987.

4. DE PALMA, R. G. Ethical, legal and economic problems in impotence practice. International Journal of Impotence Research (ISIR) 1(3/4): 150-1,1989.

5. ELLIS, H. Studies on the Psychology of Sex. New York, Emerson Books Inc., 1936.

6. GREGERSEN, E. Práticas Sexuais, a História da Sexualidade Humana. São Paulo, Livraria Roca, 1983.

7. PESSANHA, J. A. M. Vida Íntima - Enciclopédia do Amor e do Sexo. Sãó Paulo, Abril Cultural, V. I, 1981.

8. RODRIGUES Jr., O. M.; PUECH-LEẤO, P.; GLINA, S.; COSTA, M.; REIS, J. M. S. M.; REICHELT, A. C. Disfunções sexuais e a procura anterior de tratamento. Reprodução 2: 109-12, 1988a.

9. RODRIGUES Jr., O. M.; COSTA, M.; REICHELT, A. C.; GLINA, S.; REIS, J. M. S. M.; PUECH-LEÃO , P. Psicoterapia em disfunção erétil masculina com cavernosometria alterada. Arquivos Brasileiros de Medicina 62(4): 253-4, 1988b.

10. RODRIGUES Jr., O. M. A sexualidade do paciente: a vergonha do médico, e de outros profissionais de saúde. Revista Brasileira de Medicina 46(10): 511-2, 514-6, 1989.

11. SHARLIP, I. Ethical problems - editorial. International Journal of Impotence Research (ISIR)1(2): 67-9, 1989. 